In the hydro-pneumatic system the fall of the gun actuates a ram or piston working in a cylinder full of water, and communicating by an automatic valve, opening outwards from the cylinder, with an air-vessel about two and a half times the capacity of the ram, and filled with air compressed to a degree sufficient not only to support the weight of the gun, but also to raise it quickly into the firing position. When the gun is up, the air-vessel is nearly empty; when down, a volume of water equal to that of the ram displaces the air and increases its pressure, and the ratio of the fall of the gun to the stroke of the ram, and the relative velocities of the two, are so adusted that the increase of air-pressure corresponds to the increasing leverage which the gun acquires as it descends.

It is possible to provide sufficient air-pressure not only to arrest the fall of the gun, but also to absorb the energy of recoil ; but unless the gun is allowed to fall a very great distance this is not necessary, and any excess energy can be more conveniently absorbed by regulating the opening of the recoil-valve so as to throttle the water in its passage from the cylinder into the air-vessel. At first sight it might be assumed that, saving friction of the mechanism, the air-pressure which would suffice to check the fall of the gun would be sufficient to raise it again ; but a little consideration will show that this is not the case. To allow the gun to fall in the short space of time during which recoil takes place, the pressure of the air must be less than that necessary to support the gun, because its pressure rises nearly according to the ordinates of an adiabatic curve, the temperature rising in exact proportion to the work done. During the time the gun is being loaded, the heat developed in the air is dissipated, so that when the gun requires to be raised the store of heat is gone, and the air, expanding, falls in temperature by the amount of heat converted into the work of raising the gun ; the pressure consequently falls.

To meet these two sources of loss, amounting to the heat corresponding to the work of the gun falling twice the height to which it rises and falls, the energy of the discharge has to be drawn upon; it compresses the air far above its isothermal line, although that line is so fixed as to yield sufficient heat for conversion into the work of raising the gun. In addition, the energy of discharge has to provide the means of ovarcoming the friction of the machinery which resists the falling of the gun, and again resists its rising, so that, taking all the sources of loss enumerated together, the energy of recoil of even our most powerful guns is not adequate to do more than allow them to fall some 8 or 9 feet, an amount, however, sufficient for the most ample protection.

It will be readily seen that the construction of a disappearing carriage offers a number of problems of great scientific as well as practical interest. We have only dwelt upon some of the most prominent points. There remain the strains on the elevating gear, which is arranged so as to bring the gun into the same loading position, irrespective of the angle at which it is fired, and has, therefore, to communicate a sudden rotatory motion to the gun; the resistance of the levers and elevating. bars to the cross strains caused by their own inertia when brought into sudden motion sideways; the resistance offered to the water in its passage at variable velocities from the cylinder to the air-vessel, the accelerating force to be provided to raise the gun in a given time, and many minor problems which tax to the full the application of mathematics to the design of machinery.

\section{THE TOTAL SOLAR ECLIPSE OF AUGUST 19, I887.}

THE total eclipse of the sun which will occur on August 19 next, though only of average duration, will offer exceptional opportunities for observation from the circumstance that the track of the moon's shadow will be almost entirely a continental one, in striking contrast to the eclipses of the last four years, in all of which the shadow has followed a course which has been principally over the great oceans. The eclipse is technically a partial one for the principal part of Great Britain, but as it will be nearly over before sunrise, it will practically not be visible here. The middle phase will have been reached at sunrise, for places a little to the west of Berlin : and this city lying within the path of the shadow, it is just possible that it may be favoured with a sight of the phenomena of totality, though with a sun close to the horizon; for the sun will be largely obscured as it rises, and will not be quite $3^{\circ}$ high at the end of the total phase. From Prussia the shadow track passes into Russia, and the central line does not leave the borders of the Russian Empire until it reaches East longitude $112^{\circ}$. It then crosses Manchuria and the Sea of Japan, and cuts the principal island of the Japanese group a little to the north of the capital. The final portion of its course lies over the North Pacific Ocean, and except for the little island of Rico de Oro, it does not touch land again. But the path of totality not only lies mainly over land, a large number of important towns are either actually included within, or lie very close to its limits. Königsberg lies just outside. Kovno, Wilna, and Vitebsk, are well within the shadow; Wilna being nearly on the central line. At these towns, however, the sun will still be too low for them to afford desirable stations for observations, and probably the neighbourhood of Moscow will be the nearest district which will be occupied by astronomers. At Moscow itself, the eclipse will not be quite total, since that city lies just outside the southern edge of the shadow-track, but three lines of railway radiating from Moscow will afford easy access to places actually on the central line. The most westerly of these three railways is that which unites St. Petersburg with the older capital, and which passes through Twer. Twer is nearly on the central line, but a little to the north of it. The sun will have an elevation of about $16^{\circ}$ in this neighbourhood, and the maximum duration of totality is not quite two minutes and a half. At Twer itself it will be only I 24 seconds. Three parties, two German, and one French, will take up positions within the Government of which Twer is the capital. The second line runs from Moscow to Vologda, passing through Jaroslavl, which lies within but near the edge of the shadow. Petrowsk on this railway is very near the central line, and here the sun will be $2^{\circ}$ higher than near Twer, and the duration 152 seconds. The third line runs to Kineshma, which is itself very near the central line. Here the sun will be about $20^{\circ}$ high, and the total eclipse on the central line will last 156 seconds. It will not, however, be difficult to proceed to yet more favourable positions further east. From Moscow there is a line through Nijni Novgorod to Kazan, and a service of river steamers runs thence up the River Kama to Perm. Perm lies to the south of the central line, but the totality lasts there 173 seconds, whilst the sun is $28^{\circ}$ high at mid eclipse. If the weather should be favourable, Perm would be therefore a very suitable station for those astronomers who can spare the time to journey so far; for others the neighbourhoods of Petrowsk and Kineshma will afford readily accessible sites. Prof. Bredichin, Director of the Moscow Observatory, has his own private observatory only two kilometres from Kineshma, and very close to the central line ; and he has generously offered the hospitality of his house to the Royal Astronomical Society for two English astronomers, an offer which has been gratefully accepted by the Society, on behalf of Dr. Copeland and the Rev. S. J. Perry. Prof. C. A. Young also will have his station here, and a strong party of Italian and English astronomers, consisting of Profs. Tacchini and Kiccò, and Messrs. Common and Turner, will be located at no great distance away, in the neighbouring Government of Vladimir. 
The eclipse being visible in Europe and from places so readily accessible from England, no Government Expedition will be sent out to observe it. It is not probable, therefore, that any English astronomers will go so far east as Siberia. It may be hoped that Russian astronomers will make good this defect, especially as four of the principal towns of Siberia lie on the shadow-track-Tobolsk, Tomsk, Krasnoiarsk, and Irkutsk ; the first and third being close to the central line, and the sun being eclipsed when nearly on the meridian at Irkutsk. A series of Siberian stations is the more to be desired, since, as Prof. D. P. Todd has pointed out in the American Fournal for March, this eclipse offers an exceptionally favourable opportunity for a concerted scheme of observation. The path of totality coincides in a most remarkable manner with the lines of the Russian overland telegraph, so that it will be perfectly possible to select a series of stations in telegraphic communication with each other, and extending over a line of $100^{\circ}$ of longitude, with an extreme difference in the absolute time of totality of more than an hour and a half. It appears, Prof. Todd learns from a letter from Dr. S. von Glasenapp, that the Russian telegraph service may be expected to give the use of its lines at the time for astronomical purposes. It is certainly to be hoped that so unique an opportunity may not be lost; for it might well happen that some discovery, either in solar research, or of a comet or intra-Mercurial planet, might receive in this manner the most satisfactory confirmation and development.

The eclipse may also be well observed in Japan. On the west coast, Niigata, one of the Treaty ports, lies well within the shadow on the north, and Takata, a large manufacturing town, on the south, the central line passing through the large fishing-village of Idzumosaki, on the high road between the two. The Island of Sado, opposite to Niigata, which is free to foreigners, is wholly within the shadow, the central line crossing Sawa Umi Bay. The totality here lasts 198 seconds, with a sun $37^{\circ}$ high. On the east coast the important town of Mito lies almost precisely on the central line. The duration here will be 192 seconds, and the sun $35^{\circ}$ high. Japan, indeed, offers advantages for observing stations superior to those of Perm, as the sun will be considerably higher, and the duration 20 to 25 seconds longer.

The following formulæ, computed by Woolhouse's method (Nautical Almanac, 1836), from the elements of the eclipse given in the British Nautical Almanac, will supply the means for the computation of the beginning

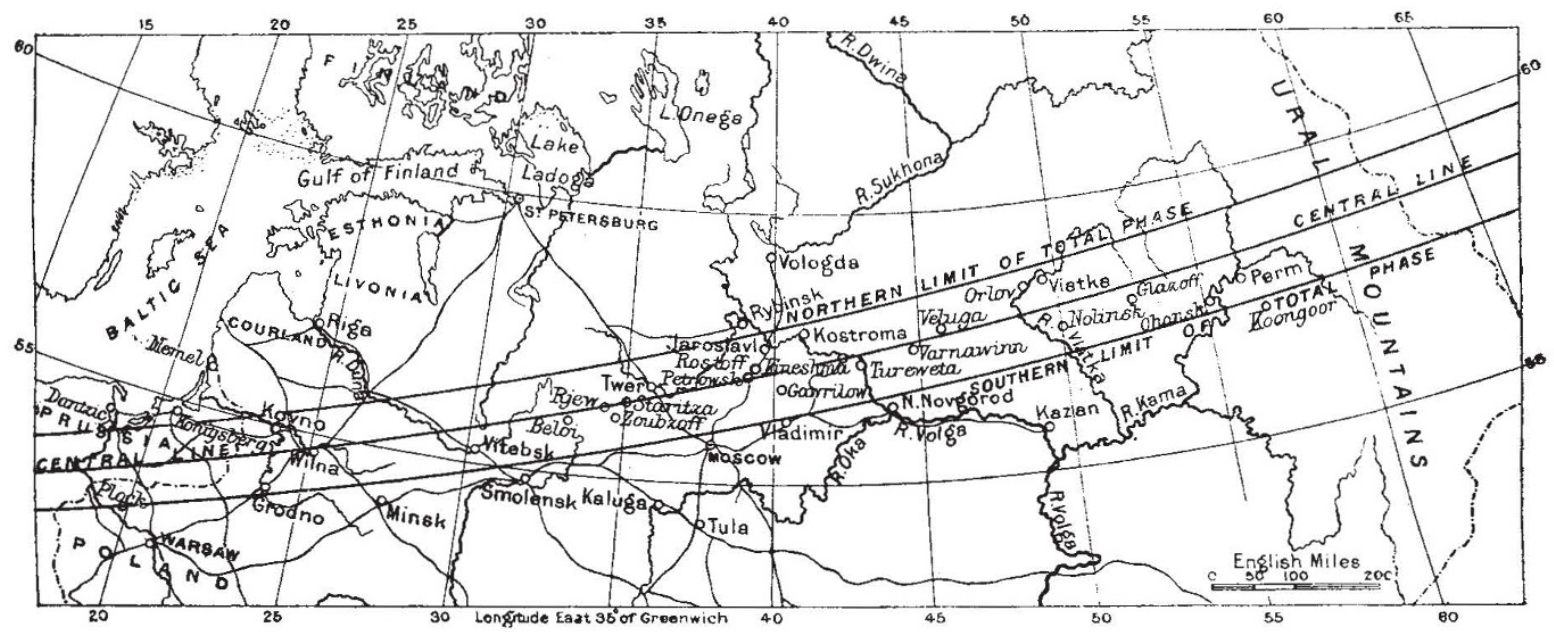

and ending of the total phase for any place not far from Perm, lat. $58^{\circ} 8^{\prime}$ N., and long. $55^{\circ} 12^{\prime}$ E. :-

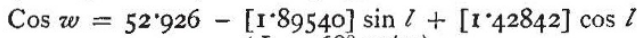
$\cos \left(L-68^{\circ} 25^{\prime} \cdot \mathrm{I}\right)$;

$t=\mathrm{I} 7 \mathrm{~h} .40 \mathrm{Om} . \mathrm{I}^{\circ} \mathrm{Oos} . \mp[\mathrm{I} \cdot 94 \mathrm{I} 68] \sin w-[3.20536] \sin l$ - [3.85031] $\cos l \cos \left(L-19^{\circ} 47^{\prime} \cdot 9\right)$.

And for determination of the latitudes of the central line, and of the north and south limits of totality in the longitude of Perm :-

$$
\begin{gathered}
n \cos (N+l)=\left\{\begin{array}{l}
-[1 \cdot 73180] \text { for } \mathrm{N} \text {. limit ; } \\
-[\mathrm{I} \cdot 72367] \text { for central eclipse ; } \\
-[\mathrm{I} \cdot 71538] \text { for S. limit. }
\end{array}\right. \\
n \cos N=[\mathrm{I} \cdot 42842] \cos \left(L-68^{\circ} 25^{\prime} \mathrm{I}\right) ; \\
n \sin N=[\mathrm{I} \cdot 89540] .
\end{gathered}
$$

As in similar formula given in NATURE for previous eclipses $l$ is the geocentric latitude, $L$ the longitude from Greenwich counted positive towards the east, and $t$ results in Greenwich mean solar time. Quantities within square brackets are logarithms, not simple numbers.

Similarly for places near Idzumosaki, lat. $37^{\circ} 38^{\prime} \mathrm{N}$., and long. I $38^{\circ} 49^{\prime}$ E., we have :--

$$
\begin{aligned}
& \operatorname{Cos} w=+53.9763-[\mathrm{r} \cdot 84932] \sin l \\
& +\left[\mathbf{I}^{\cdot} 53^{2} 39\right] \cos l \cos \left(L-24^{\circ} 5^{\prime} \mathrm{I}^{\prime} \cdot \mathrm{I}\right) \text {; } \\
& t=17 \text { h. } 32 \mathrm{~m} .24^{\circ} 9 \mathrm{~s} \text {. } \mp\left[\mathrm{I} \cdot 99^{\circ} 43\right] \sin w-\left[3^{\circ} 4509 \mathrm{I}\right] \sin l \\
& \text { - }[3.85537] \cos l \cos \left(L+10^{\circ} 4^{\prime} \cdot 7\right) \text {. }
\end{aligned}
$$

And for central line and limits :-

$$
n \cos (N+l)-\left\{\begin{array}{l}
-[174018] \text { for } \mathrm{N} \text {. limit } \\
-[\mathrm{I} \cdot 73220] \text { for central eclipse } \\
-[\mathrm{r} \cdot 72408] \text { for S. limit. }
\end{array}\right.
$$

\section{THE STEERING OF H.M.S. " $A \mathcal{F} A X$."}

W

HEN H.M.S. Ajax was first sent to sea, her steering qualities were found to be very defective, especially at high speeds, the most objectionable and perplexing characteristic of her behaviour being a tendency to require a large angle of helm to keep her on a straight course. This helm tendency was sometimes on one side and sometimes on the other, generally remaining the one or the other for some time unchanged, but occasionally changing sides without warning or apparent cause. On such occasions, at full speed, the ship had been found to fly off her course at a right angle before she could be mastered by reversing the helm.

In a lecture on this subject, lately delivered before the Royal United Service Institution, Mr. R. E. Froude summarised as follows the causes to which such behaviour might be colourably attributed in ships of the type of the Ajax, namely, flat-bottomed and full-ended, particularly in the run: (I) want of "directive character" (as he phrases it) 